\title{
AS AFINIDADES ELETIVAS NA SOCIOLOGIA DA CULTURA JURÍDICA
}

\author{
Eduardo José da Fonseca Costa \\ Aluno do Curso de Graduação da Faculdade de Direito da Universidade São Paulo
}

Ah! Maldito conúbio incestuoso

Dessas afinidades eletivas

De onde quimicamente tu derivas,

Na aclamação simbiótica do gozo!

(Augusto dos Anjos)

Resumo:

Em razão do Positivismo Comtista, a terminologia das Ciências Naturais ainda tem sido freqüentemente empregada na formulação dos conceitos sociológicos. Entretanto, as idéias fundamentais das ciências sociais precisam ser encaixilhadas em palavras capazes de descrever satisfatoriamente a fluidez dos fenômenos socioculturais. A expressão alquímico "afinidade eletiva", por exemplo, tem sido convertida em conceito sociológico a fim de explicar as aliạnças nada mecânicas entre sistemas socioculturais. Ela pode também ser útil para a Sociologia da Cultura Jurídica na elucidação das relações existentes entre sistemas jurídico-compreensivos e certas tendências políticas, econômicas e religiosas.

Abstract:

Natural Sciences' terminology has been still used frequently to elaborate the sociological concepts on account of Contism. Nevertheless the fundamental ideas of social sciences must be framed into words capable of describing satisfactorily the flowing sociocultural phenomena. The alchemical expression "elective affinity", for example, has been turned into a sociological concept in order to explain the non-mechanical alliances between sociocultural systems. It can be also useful to Sociology of Juridical Culture for making clear some relations between comprehensive systems about Law and some political, economical and religious tendencies.

Unitermos: afinidades eletivas; sociologia da cultura jurídica; sistemas socioculturais. 
Sumário:

1. Introdução.

2. Núcleos Fundamentais.

3. Positivismo Científico.

4. Afinidades Eletivas.

5. Níveis de Afinidade.

6. Nazismo e Teoria Pura do Direito.

7. Conclusão.

1. Introdução.

O presente estudo pretende cuidar da Cultura Jurídica como objeto da Sociologia.

A palavra "cultura" diz, em sentido objetivo, ${ }^{1}$ com tudo aquilo que se adquire, se apreende e pode ser transmitido por herança social. Consiste, desta forma, num conceito complexo no qual seriam implicados elementos desde a ideologia, as crenças, os costumes, os hábitos, os usos e os costumes, os quais permitem ao homem sempre um certo grau de controle sobre o meio social.

Como "cultura jurídica", entendamo-la, pois, como um conjunto de conhecimentos predominantes de idéias jurídicas estabelecidas em uma determinada sociedade. Tratam-se, como entes culturais que são, de bens exteriores objetivos transmissíveis por processos de herança por aprendizagem, dos quais participa a pessoa humana ao interagir socialmente. Neles certamente se compreendem os sistemas jurídico-compreensivos, tanto dogmáticos quanto zetéticos.

Consiste este estudo mais precisamente na compreensão do relacionamento destes sistemas compreensivos com outros sistemas socioculturais. Por certo, a explicação destas relações complexas deve prescindir do aparelho conceitual desditosamente ritualizado em que ainda se funda a Sociologia contemporânea, principalmente a Sociologia Jurídica.

Em verdade, a Sociologia do Direito, principalmente a desenvolvida no Brasil, tem padecido de duas características. Em primeiro lugar, dentro da experiência jurídica, o único fato social sobre o qual se tem debruçado a Sociologia

1. Sobre os conceitos objetivo e subjetivo da cultura, ver, p.ex., Dicionário de Sociologia, Porto Alegre, Globo, 1974, p. 322. 
Jurídica é o direito-norma, prescindindo por completo da compreensão sociológica do direito-ciência. Em segundo lugar, a Sociologia Jurídica se tem comportado como uma receptadora sempre passiva de inovações metodológicas trazidas pelos outros ramos da Sociologia, revelando-se incapaz, portanto, de desenvolver um aparato conceptual menos ritualizado e mais sintonizado com o seu específico objeto de estudo.

Este texto, por enquanto, limita-se tão-somente à pretensão de lutar contra o primeiro vício. Por isto, trazemos à baila a experiência vivida (erlebnis) por sociólogos europeus da cultura na utilização do conceito de afinidade eletiva, tentando mostrar a suas benesses quando trazida ao entendimento da dinâmica social dos sistemas jurídico-compreensivos.

2. Núcleos Fundamentais.

Para o cientista brasileiro Mário Schenberg, centros nervosos do pensamento constituem-se por idéias fundamentais, as quais por serem fundamentais, são dotadas de complexidade, obscuridade, densidade e mistério. Quando se descobre um núcleo fundamental, quase se não encontra a sua linguagem para que faça pleno sentido e seja compreendido no contexto cultural no qual se revela. Desta maneira, ao perceber-se uma idéia fundamental, transcende-se tanto a individualidade como o contexto social no qual se está inserido. ${ }^{2}$

Segundo Schenberg, o desenvolvimento do núcleo fundamental numa determinada sociedade depende do enquadramento que sofre as estruturas mentais nela vigentes. Ao adentrar no contexto social transfigurado por seus padrões culturais, o núcleo fundamental acaba também por transfigurar este contexto, uma vez que não se associa à normalidade existente. Assim, quando uma cultura proclama ter dominado um núcleo fundamental, ele sempre acaba escapando-lhe às mãos, apresentando novidades absurdas, que subvertem essa cultura que se intitula como acabada. Aconteceu exatamente assim na Física com as idéias de espaço, tempo, energia, causalidade e continuidade, por exemplo.

Em famosa conferência em que dava um panorama geral da Ciência no fim do século XIX, Lorde Rayleigh afirmava que quase tudo na Física já se havia

2. Sobre o pensamento schenberguiano acerca da História da Ciência, ver José Luiz Goldfarb, Voar também é com os homens: o pensamento de Mário Schenberg, São Paulo, EdUSP, 1994. 
compreendido, com exceção de três detalhes tão logo explicáveis: a experiência de Michelson e Morley, a irradiação do corpo negro e o efeito fotoelétrico. Contudo, sem importância aparente, nestes detalhes encontravam-se exatamente os germes das teorias da Relatividade e do Quanta.

Vê-se que a Ciência, reputada como simples e formalmente estruturada, exige uma dimensão fundamental onde os pensamentos seguem caminhos diferentes da lógica formal, num processo ziguezagueante dotado de elevada carga intuitiva e imaginativa. Por vezes, a Ciência progride mesmo quando se volta para uma idéia que já existia antes, sem que, no entanto, se volte do mesmo modo com que ela havia sido formulada anteriormente. Aquilo que era falso em determinado período, coisa do passado e pensamento primitivo portanto, pode repentinamente reflorescer num novo contexto com intensidade surpreendente. Toda riqueza do passado se recupera e, sendo trabalhada em nível de núcleo fundamental, surge recriada, indicando os novos caminhos científicos.

Nesse nível mais fundamental e menos sistematizado do pensamento, o diálogo entre culturas e tradições aparentemente conflituosas instaura-se com mais intensidade, vez que, pelas suas características não formalmente estruturadas, o núcleo fundamental pode aparecer em distintos contextos históricos. Tal posicionamento, portanto, exige um pensamento a um tempo revolucionário e tradicionalista, que pretende reler o passado e transformar o presente para penetrar no futuro.

\section{Positivismo Científico.}

Determinadas intuições podem estar séculos à frente de seu florescimento científico, muitas vezes podendo depender para tanto do surgimento de lógicas e linguagens formais ainda não conhecidas até o momento em sua história cultural. Até mesmo porque o processo científico de criação nẳo tem em vista fazer com que tudo caiba em uma lógica, mas descobrir a própria lógica que nas coisas se encerra. E a ciência parece revelar essa lógica tão-somente para o pensamento criativo.

A despeito de ser repetido em relação ao pensamento das Ciências Naturais, esse discurso aplica-se plenamente às questões primordiais que envolvem as Ciências Humanas, dotadas também estas de seus próprios núcleos fundamentais. Um deles parece ser a idéia de causalidade, freqüentemente empregada para a 
explicação das relações entre sistemas socioculturais, por força de uma longa e pesada tradição positivista. Esta tradição, diga-se de passagem, um século após Auguste Comte, ainda faz com que a Sociologia continue a tomar emprestada sua terminologia conceptual da Física ou da Biologia.

Apesar da evidência de que exibem os sistemas socioculturais traços fundamentais únicos em relação a sistemas físicos e aos organismos biológicos, ainda parece persistir a questão dos motivos pelos quais as teorias dos primeiros continuam a valer-se de estéreis analogias com os últimos. A teoria sociológica dominante, por exemplo, restou edificada sobre os modelos de sistemas mecânico e orgânico que se formularam durante os séculos anteriores e que se encontram totalmente inadequados ao tratamento do tipo de sistema representado pela esfera sociocultural. As respostas infelizes envolvem, indubitavelmente, o grande sucesso e prestígio das ciências físicas e as semelhanças e afinidades sedutoras não raro superficiais entre as esferas biológica e social, desenvolvidas por intelectos de outras eras, respeitáveis, porém, amiúde grosseiramente inexatos. ${ }^{3}$

Pergunta-se: não estaria na hora de romper com essa tradição positivista e recorrer a um fundo espiritual e cultural mais vasto, que, em decorrência de sua riqueza semântica, representasse com maior proximidade a textura fluida de fatos socioculturais? Por que não utilizar o vasto campo semântico das religiões, dos mitos, da literatura e até mesmo das tradições esotéricas, para fecundar a linguagem das ciências sociais, assim como tomou Max Weber o conceito de carisma da teologia cristã, ${ }^{4}$ e Karl Mannheim o conceito de constelação da astrologia clássica? ${ }^{5}$ Não se disporia, desta maneira, de um instrumental muito mais apto à compreensão dos núcleos fundamentais presentes nas Ciências Sociais?

3. Sobre o domínio dos modelos mecânico e orgânico na teoria sociológica, ler Walter Buckley, $A$ Sociologia e a Moderna Teoria dos Sistemas, trad. Octavio Mendes Cajado, São Paulo, Cultrix, EdUSP, 1971.

4. Max Weber, Economia y Sociedad, México, Fondo de Cultura Económica, 1977, p. 193 e ss.

5 Karl Mannheim, O Problema de uma Sociologia do Conhecimento, trad. M. Gama e I. Dutra, in Sociologia do Conhecimento, Rio de Janeiro, Zahar, 1967, p. 28. 
4. Afinidades Eletivas.

Esse posicionamento epistemológico, no entanto, parece angariar adeptos no campo da investigação dos fenômenos socioculturais, principalmente com a crescente necessidade de lidar-se com relações complexas e dinâmicas entre partes, as quais são também complexas e mutáveis.

Em 1809, J. W. Goethe (1749-1832) compõe uma obra clássica para mostrar a imprevisibilidade do futuro de um homem. $\mathrm{Na}$ novela Die Wahlverwandtschaften (As Afinidades Eletivas), Goethe, retornando aos velhos alquimistas possivelmente através do químico sueco Torbern Bergman, refere-se ao fenômeno químico em que dois elementos associados, sob atração de dois outros elementos, se desagregam para formar dois novos pares (assim, as moléculas $\mathrm{AB}$ e $\mathrm{CD}$ reagem para combinarem-se de novo em $\mathrm{AD}$ e $\mathrm{CB}$ ). Da mesma forma, a vida tranqüila do casal aristocrata Barão Edouard e Condessa Charlotte, que vivem isolados numa casa de campo na Itália do final do século XVIII, subitamente tem a sua aparente harmonia transformada pela chegada de dois hóspedes o velho amigo do barão e uma jovem protegida da condessa. Uma série de acontecimentos trágicos e passionais começam a acontecer. O autor mostra as forças da natureza aparentemente ocultas em atuação sobre relações pessoais e sociais. Goethe fala portanto sobre um mundo de "incertezas inextricáveis" A obra acaba detectando os paradoxos da consciência racional que se consolidou com o Século das Luzes.

Especialmente na obra de Max Weber, a mesma expressão (wahlverwandtschaft) transmuta-se em um conceito sociológico para analisar a relação entre doutrinas religiosas e formas de comportamento econômico, mais particularmente entre a ética protestante e o espírito do capitalismo industrial. Segundo Weber, "em face do enorme embaralhamento de influências recíprocas entre bases materiais, formas de organização sociais e políticas, contexto espiritual das épocas da Reforma, somos obrigados a pesquisar, de início, se algumas afinidades eletivas (wahlverwandtschaften) são perceptíveis entre formas da crença religiosa e as da ética protestante. Ao mesmo tempo, é preciso elucidar, na medida do possível, de que modo e em que direção o movimento religioso, em conseqüência de suas afinidades eletivas, influenciou o desenvolvimento da cultura material" 6

6. Max Weber, L'ethique protestante et l'esprit du capitalisme, Plon, 1967, p. 107; trad. revisada e corrigida cf. original, Max Weber, Gesammelte Aufsütze zur Religionssoziologie, Tübingen, J. C. B. Mohr, 1922, p. 83. Em português, wahlverwandtschaft tem sido traduzido como "correlação". cf. "A ética protestante e o espírito do capitalismo", trad. M.I.Q.F. e T.J.M.K. Szmrecsányi, Brasília, UnB, São Paulo, Pioneira, 1981, p. 62. 
Para Weber, pois, a afinidade eletiva pode articular estruturas socioculturais sem que entretanto haja a formação de uma substância nova ou uma modificação essencial dos componentes iniciais - mesmo se a interação tem conseqüências eficazes, particularmente ao reforçar a lógica própria de cada cultura. Ademais, o conceito aqui se limita somente a afinidades entre visões de mundo e classes sociais.

Vilipendiando assim como Weber uma reflexão mais detida acerca da significação conceptual de afinidade eletiva, o sociólogo Karl Mannheim escreve em seu estudo sobre o pensamento conservador que "na confluência (zusammenfliessen) de duas orientações de pensamento, a tarefa da sociologia do conhecimento é encontrar os momentos nas duas correntes que revelavam, antes mesmo da síntese, uma afinidade interna (innere Verwandtschaft) e que, assim, tornava possível uma unificação" 7

Embebendo-se na tradição da Alquimia, na obra de J. W Goethe e recuperando o conceito de afinidade eletiva que importantes sociólogos já haviam sugerido em trabalhos clássicos, Michel Löwy reconstituiu brevemente em sua obra o itinerário deste termo, para captar toda riqueza de significações havidas ao longo de seu périplo espiritual. ${ }^{8}$ Ensaia um desvendamento ao acesso das correspondências nada mecânicas entre movimentos, formas e tendências culturais. Investiga elos esquecidos entre religião e política, fazendo combinar a formação marxista incorporada em décadas de estudo com sua experiência riquíssima de sociólogo da cultura.

Seu livro Redenção e Utopia trata de uma geração de intelectuais judeus surgidos no fim do século XIX, na Europa Central, cujas obras imprimiram fortes marcas na cultura moderna. Objetiva desvendar as linhas da história capazes de reunir a ação e o pensamento de figuras tão dispares como Walter Benjamim, Györg Lukács, Franz Kafka, Ernst Bloch, Martin Buber, Gershom Scholem, Erich Fromm, entre outros. Para tanto, recupera com elegância o conceito romântico e alquímico de afinidade eletiva, numa preciosa mostra de imaginação sociológica que ilumina os vínculos profundos entre o messianismo judaico, o romantismo alemão e a utopia social. Para valorizar-lhe a potencialidade científica, Löwy ressalta a

7. Karl Mannheim, Wissenssoziologie, Berlim, Luchterhand, 1964, p. 458. Sobre as afinidades, ver também Karl Mannheim, op. cit., p. 28.

8. Michael Löwy, Redenção e Utopia: o judaísmo libertário na Europa Central: um estudo de afinidade eletiva, trad. Paulo Neves, São Paulo, Companhia das Letras, 1989. 
possibilidade de mostrar-se o conceito, um instrumento fecundo e adequado para o estudo das relações entre ética cavaleiresca e doutrina medieval da Igreja, entre Cabala e Alquimia no XVI, entre psicanálise e marxismo no século XIX, entre idealismo alemão e judaísmo, etc. ${ }^{9}$ De nossa parte, podemos acrescentar as relações entre Mecânica Quântica e Budismọ Tântrico na comunidade científica do século $\mathrm{XX}$ e entre positivismo jurídico e totalitarismo no período entre-guerras.

\section{Níveis de Afinidade.}

A afinidade eletiva é tida como um tipo muito particular de relação dialética que se estabelece entre duas configurações socioculturais, irredutível a determinações causais diretas ou a "influências" no sentido tradicional, a qual não se há de confundir com as afinidades ideológicas inerentes às variantes duma mesma corrente social (socialismo e igualitarismo, p. ex.). Trata-se, a partir duma certa analogia estrutural, de um movimento de convergência, atração recíproca, confluência ativa, uma combinação capaz de chegar à fusão. Portanto, percebe-se que na utilização sistemática do conceito, torna-se mister a elaboração de um certo número de precisões, levando-se em conta, pois, que uma afinidade eletiva comporta vários graus. ${ }^{10}$

Como primeiro grau de atração, Michael Löwy identifica a afinidade pura e simples, o parentesco espiritual, a homologia estrutural, a correspondance (no sentido empregado por Charles Baudelaire) entre dois universos culturais, cada qual situado em uma esfera bem distintas, mas que se reforçam, se alimentam e se estimulam mutuamente. $\mathrm{O}$ conceito perde a conotação mística originária e passa a designar o sistema de analogias recíprocas que atravessam o universo, as relações íntimas e secretas das coisas. Mister sublinhar que a afinidade pura e simples é uma analogia ainda estática, que cria a possibilidade mas não a necessidade de uma convergência ativa, pois a dinamização da analogia e sua evolução para uma interação ativa depende de uma constelação de condições históricas concretas, como mutações econômicas, reações de classes, movimentos culturais, acontecimentos

9. No Brasil, ver, p. ex., Renato Lessa, Ceticismo e Liberalismo: reflexões sobre uma possível afinidade eletiva, in Revista de Sociologia e Política, n. 3/ nov. 1994, p. 32: "O argumento básico de Laursen é o de que existe uma political stance no ceticismo, e que esta mantém com o liberalismo relação de forte afinidade" (o grifo é nosso).

10. Michael Löwy, op. cit., pp. 17-18. 
políticos, etc. Uma afinidade eletiva nunca se dá no vazio ou na placidez da espiritualidade pura.

O segundo grau está na eleição, na atração recíproca, na mútua escolha das duas configurações socioculturais, o que conduz certas formas de interação, de estimulação recíproca e de convergência, sem que entretanto as duas estruturas deixem de permanecer separadas. Pressupõe-se uma distância prévia, uma certa heterogeneidade ideológica. Aqui parece encontrar-se a afinidade eletiva entre ética protestante e espírito capitalista.

O terceiro grau se encontra na articulação, na combinação ou na "liga" entre os parceiros socioculturais, podendo resultar em diferentes modalidades de união: $a$. O que se poderia chamar de "simbiose cultural" (na qual as duas figuras permanecem ainda bem distintas, mas estão organicamente associadas); $b$. A fusão parcial e, $c$. A fusão total.

O quarto nível se dá na criação de uma figura nova a partir da fusão dos elementos constitutivos, eventualidade ausente das análises de Weber. Contudo, segundo o próprio Löwy, torna-se sempre muito difícil o estabelecimento da distinção entre os dois últimos graus de afinidade eletiva: marxismo freudiano seria articulação de dois componentes ou forma de pensamento nova, distinta tanto da psicanálise quanto do materialismo histórico?

\section{Nazismo e Teoria Pura do Direito.}

O conceito sociológico de afinidade eletiva permite enriquecimento e dinamização na análise relacional entre fenômenos econômicos, políticos, religiosos e jurídicos. Vejamos o exemplo da obra de Hans Kelsen.

A teoria da norma fundamental (Grundnorm) sempre provocou celeumas, principalmente por ser ela tida como o fundamento mesmo da ordem jurídica; logo, todo o universo normativo se valida e se legitima em função dela. Qualquer norma somente se tem como jurídica e como legítima se estabelecida conforme as prescrições contidas na norma fundamental. Fonte, portanto, de juridicidade e de legitimidade, a norma fundamental reputa-se neutra, sendo que dela não se pode exigir que seja justa. Mesmo uma norma fundamental injusta valida e legitima o direito que dela decorre.

Essa posição custou a Hans Kelsen a crítica desmerecida de ter servido, ainda que indiretamente, ao regime dos nazistas. Justamente ele, que havia 
fugido da Alemanha para instalar-se na Universidade de Berkeley, onde permaneceria até a morte, com sua norma fundamental via-se constrangido a reconhecer, como realmente fê-lo ao chegar ao exílio nos Estados Unidos, que o direito nazista era plenamente válido e legítimo, posto que injusto e imoral. ${ }^{11}$

Deste episódio, tem-se como Hans Kelsen defendeu ardorosamente a neutralidade científica aplicada à ciência jurídica. À ciência do direito (Rechtswissenschaft) não caberia elaborar julgamentos morais nem avaliações políticas sobre o direito vigente. Kelsen obviamente, não-só por ser judeu, mas por suas posições ideológicas em defesa da democracia, jamais teve simpatia pelo nazismo. No entanto, entre nazismo e positivismo kelseniano viu-se claramente uma reciprocam affinitatem, um enlace químico que parecia proceder menos de ódio do que de amor, configurando-se, pois, o segundo nível de afinidade eletiva detectado por Michael Löwy. Denunciou-se daí as conseqüências moral e socialmente mais negativas do positivismo, podendo-se falar polemicamente da reductio ad Hitlerum de tal doutrina. ${ }^{12}$

As convergências ativas entre Nazismo e "Teoria Pura do Direito" (Reine Rechtslehre), nos moldes teóricos da afinidade eletiva, potencializam-se exatamente naquele momento em que o Partido Nacional-Socialista dos Trabalhadores Alemães, fundado em 1919 por Adolf Hitler, ocupa eleitoralmente as instâncias do poder político alemão em 30 de janeiro de 1933 e passa a exigir um sistema jurídico-compreensivo que, de mãos dadas com o seu programa contraditório dos "vinte e cinco pontos" faça com que as duas orientações de pensamento confluam para uma estatolatria que condena as liberdades democráticas.

Estudando os antecedentes históricos do Totalitarismo moderno, em especial o despotismo oriental dos indianos e dos chineses, Barrington Moore e Wittfogel, embora aquela não co-dividindo a colocação deste, puderam sublinhar a obra de estandardização e de uniformização da burocracia estatal, a existência de um sistema bem desenvolvido de espionagem e de delação recíproca e especialmente uma doutrina política caracterizada por um racionalismo amoral interessado

11. Ver Tércio Sampaio Ferraz Jr., "Porque ler Kelsen, hoje". in Cultura, de O Estado de $S$. Paulo, 01.11.81, n.73, pp. 12-13

12. Sobre positismo jurídico e regime totalitário, p. ex., Norberto Bobbio, O Positivismo Juridico. Lições de Filosofia do Direito, compilados por Nello Morra, trad. e notas Márcio Pugliesi et alii, São Paulo, İcone, 1995, pp. 224-225. 
unicamente na técnica política mais eficaz. ${ }^{13}$ Ora, se uma afinidade eletiva se instaura justamente a partir da equivalência de premissas entre dois sistemas culturais, podemos afirmar que um dos elos de ligação entre a teoria pura do direito e a doutrina nazista se estabelece entre o racionalismo amoral do movimento nacionalista alemão e as concepções avalorativas dos positivistas.

Outro fator de reciprocam affinitatem entre os dois sistemas culturais encontra-se na nota de repressividade que os caracteriza. Antibolchevismo, antiindividualismo, anti-semitismo, irracionalismo, imperialismo, racismo, princípio da liderança e exaltação da guerra, alguns dos principais pontos doutrinários do Nazismo, para efetivarem-se na esfera empírico-sociológico, exigiam um aparato estatal altamente repressor, capaz de reputar-se o non plus ultra da degradação individual nos campos de concentração e nas operações de genocídio. Com relação ao positivismo kelseniano, este entendia o Direito simplesmente como uma ordem coativa da conduta humana, ou seja, uma ordem social que se rege contra situações socialmente perniciosas por meio de atos de coação como a privação da vida, da saúde, da liberdade, de bens econômicos e outros aplicados mesmo contra a vontade de seu destinatário.

Ademais, Hans Kelsen e demais positivistas acabaram legando estruturas mentais profundamente influenciadas pela concepção hegeliana de Estado, que assumira uma importância notável junto ao positivismo jurídico alemão da segunda metade do século XIX. Segundo esta concepção, o Estado consiste na manifestação suprema do Espírito Absoluto em seu devir histórico, sendo ele, pois, o fim último ao qual os indivíduos estão subordinados. Evidentemente, tal maneira de entender o Estado não configura uma teoria, mas uma ideologia, uma vez que não descreve o Estado assim como ele é, mas como se desejaria que fosse.

Nietzsche, na voz eloqüente do seu Zarathustra, já previa os riscos intelectuais a que se expõem involuntariamente os herdeiros de uma tradição cultural qualquer ("Nicht nur der Vernunft von Jahrtausenden, auch ihr Wahsinn bricht an uns aus. Gefährlich ist es, Erbe zu sein"). Precisamente diante de uma constelação concreta de fatores históricos, as insanidades da tradição estatólatra contemporizavam-se, nos pressupostos básicos da Reine Rechtslehre, em uma afinidade de sentido com o Nazismo.

13. Mario Stoppino, "Totalitatismo", in Dicionário de Política, por Norberto Bobbio et alii, trad. João Ferreira et alii, $2^{2}$ ed., Brasília, UnB, 1986, p. 1251. 
Nesses termos, só se pode redimir Kelsen por meio de uma análise sociológica do isomorfismo espiritual existente entre dois universos culturais originariamente autônomos e ideologicamente independentes, mas que desgraçadamente guardavam incubadas entre as suas premissas profundas correspondances.

7 Conclusão.

- Este estudo cingiu-se tão-somente a exemplificar timidamente as afinidades eletivas havidas entre a teoria pura do direito e o nazismo, portanto, entre um sistema jusfilosófico e uma doutrina política de caráter fascista. De certo, tornam-se cientificamente promissores estudos de afinidades eletivas entre a Teoria Autopoiética do Direito e o Neocorporativismo, entre a Teoria Tridimensional do Direito e o Integralismo no Brasil, entre a Escola do Direito Livre e as Utopias Sociais Libertárias, até mesmo entre a Teoria Pura do Direito e o Neoliberalismo Econômico, como crêem alguns. Muitas são, pois, as possibilidades de reciprocam affinitatem entre os ramos de estudo jurídico e as mais diversas formas de Weltanschaung social.

São Paulo, maio de 1997. 